\title{
Travel, space and transformation
}

Denise Doyle, University of Wolverhampton

\begin{abstract}
Under the theme of transformation through physical and non-physical travel, this article explores known and unknown worlds, and real, imagined, and virtual spaces, through collaborative art and performative writing practices. The weaving of real stories and aspirations, and the notion of the journey that extends beyond or breaks through cultural boundaries and stories of personal transformation are themes that are explored in particular. The article further explores virtual worlds as spaces of and for the imagination, where the entanglement of the physical with the virtual is exploited for its creative potential. In particular, there are opportunities to further explore our understanding of the transforming act of virtual and imagined travel through an exploration of the experience of time, space and place.
\end{abstract}

Keywords: transformation. travel, performative writing, physical, virtual, imagination

\section{Introduction}

Contemporary astronomy enables us to contemplate the wonders of the universe with its evocation of the endless frontiers of outer space; another cosmology of space and time suggests a difficulty in determining where the border of the real and imagined lies. From dreams of early space travel to the echoes of longing in journeys as chance encounters through space and time, artists have long explored the theme of the unknown. Conceivably, even the cultural myths of astronauts and avatars are one and 
the same: that of bodies travelling in unknown spaces and time. The decades of the 1950s and 1960s can be seen as a time when, with new tools and technologies, the exploration of the extreme limits of outer space developed new imaginaries of space itself. In a contemporary context, online virtual space and, more particularly, the 3D virtual worlds available for exploration are providing similar outer or extreme limits of worlds - yet it is the nature of the space that is created and experienced that is more significant in a contemporary context. How do we make sense of these opportunities for new forms of 'travel' being offered by new technologies? Rather than a geographically distant far-awayness that is imagined (and sometimes experienced), it is the 'nature' of the space along with a new type of traveller that is being created that is of interest here.

Two strands of travel will be explored in this article: first, that of travelling in physical space, though encountered as extreme and unknown, where the experiences of the physical body become distorted or challenged; second, through the imagined and virtual spaces that are not physical, yet are encountered as real. The article explores the common thread that it is bodies that act as interpreters of space - both in the body of the astronaut (and those that have experienced their bodies in zero gravity) and in the virtual body of the avatar (or the virtuanaut). Using examples of a range of art projects, the chapter explores how technology can aid the exploration of new forms and methods of 'travelling in and through' space. In particular, there are opportunities to further explore the poetics of the transforming act of virtual and imagined travel through an exploration of the experience of time, space and place. My interest in the notion of Wanderingfictions Story (my virtual avatar counterpart) as a form of virtual traveller, moving between the physical and the virtual, travelling between the virtual and the 
imagined (and quoted at the start of this chapter), became the basis of a range of projects including Metadreamer (2009), which will be discussed later in the chapter.

\section{Art, space and technology}

There has been a relationship between art and virtual space at least since the Renaissance, with the invention of linear perspective. More recently, in the field of Art and Technology, the relationship between art and virtual space appears implicit in its scope and engagement (Ettlinger 2009; Grau 2003; Lindstrand 2007). However, Or Ettlinger describes the 'fog of multiple meanings around the term the virtual' (2009: 6), and he suggests that, in fact, contemporary and digital art has lost its interest in the art of illusion and is only now marginally concerned with the pictorial. There is a history to the relationship between art and the virtual, which spans a number of decades from the early 1990s, from early experiments in virtual environments (Davies 1995, 1998; Gromala and Sharir 1994; Laurel and Strickland 1993; Sermon 1992) to the networked environments of the early twenty-first century and to the networked virtual spaces found in online virtual worlds such as Second Life. There is an argument that, as soon as linear perspective was invented, painting became another kind of virtual space, and, in fact, Lindstrand suggests that 'before the invention of linear perspective, spatial experience was detached from imagery. Once the tools to depict three-dimensional space on a two dimensional surface were developed, architecture and the understanding of space leaped into a new era' (2007: 354). For Lindstrand, the possibility for the viewer to imagine himself or herself walking around inside a painting opened up a whole new chapter in art as well as causing a fundamental shift in the experience of space. Ettlinger would most certainly agree with this perception of space. In developing 'The Virtual Space 
Theory', he states that at its heart lies 'the interpretation of virtual space as the overall space which we see through pictorial images, and of "virtual" as describing any visible object which is located inside of that space' (Ettlinger 2009: 6).

The notion that the concept of space can be seen as Cartesian, definable and contained is at odds with the concept of space as lived, as experienced, such as the 'Thirdspace' that Edward W. Soja describes, and is discussed further below (1996). In The Production of Space (1991), Henri Lefebvre attempts to define the experience of space from both a metaphysical and an ideological perspective. Initially he outlines two terms in relation to space, that of the illusion of transparency and that of the illusion of opacity (or the realistic illusion). Of the illusion of transparency, he writes that the emphasis of the written word is to the detriment of what he terms social practice. In what he describes as the grasping of the object by the act of writing, he suggests that this is supposed to bring the

non-communicated into the realm of the communicated ... such are the assumptions of an ideology which, in positing the transparency of space, identifies knowledge, information and communication ... The illusion of transparency turns out ... to be a transcendental illusion: a trap, operating on the basis of its own quasi-magical power. (Lefebvre 1991: 28-29)

In turn, the illusion of opacity, of substantiality, is philosophically closer to naturalistic materialism. However, and most interestingly, Lefebvre continues to say that the two illusions are not necessarily in opposition to each other and do not 'seek to destroy each 
other'. Rather, he argues that 'each illusion embodies and nourishes the other. The shifting back and forth between the two, and the flickering or oscillatory effect that it produces, are thus just as important as either of the illusions considered in isolation' (Lefebvre 1991: 29). This flickering, from opaque to transparent to opaque again, these oscillations, suggests a complex system of relationships between a space and the objects found in that space. Yet, Lefebvre (1991: 29) writes that it is the texture of space that allows us to create space through social practice as sequences of acts that become a signifying practice in itself. Ettlinger's and Lefebvre's understandings of space appear at odds with each other.

An article by Axel Stockburger, Playing the Third Place (2007), extends Lefebvre's ideas to the work of Soja and his definition of what he terms the Thirdspace. As Stockburger notes, beyond the dualism of subject and object Lefebvre suggests that spaces can be understood within the triad of the perceived, the conceived and the lived. According to Stockburger, Soja 'identifies perceived space (Firstspace) with the real, and conceived space (Secondspace) with the imaginary, leading to lived space (Thirdspace), as a field of both, imagined and real' (Stockburger 2007: 232).

Stockburger continues with his interpretation in the context of game space and describes the hybrid mix between real and imagined spaces created through digital game universes as resonating strongly with the concept of Thirdspace. He notes that 'this insight is crucial because it defies the idea of computer games as merely "virtual" or purely imaginary spaces. It is precisely the interaction between real and imagined spatiality that makes this medium so compelling and unique' (Stockburger 2007: 232). A concept of space that suggests a mixed experience of both real and imagined spatiality proves to be useful when considering online and networked spaces, whether 
they are games-based or not.

\section{Technology and travel}

From early writings on virtual reality (such as Damer 1998; Heim 1993; Heudin 1999; Rheingold 1991; Schroeder 2002), to Jones (2006: 4) suggesting that 'virtual reality is the contemporary and future articulation of the philosophical and psychological question of how we define (and create) reality', the issues, definitions and experience of reality find rich and challenging ground in virtual environments. Writing in 2001, Grosz (Grosz 2001:40) describes virtual realities as 'computer-generated and [computer]-fed worlds that simulate key elements of "real space" or at least its dominant representations - for example, its dimensionality, its relations of resemblance and contiguity - acting as a partial homology for a "real space" within which it is located'.

The early use of virtual environments for artistic practice was explored in a series of projects undertaken at the Banff Centre, Canada, in the early 1990s and subsequently documented in Immersed in Technology: Art and Virtual Environments (M. A. Moser, 1996). In the preface to the book, Douglas Macleod, the Project Director, likens this 'moment of virtual reality' to a similar moment in time when Vertov's Man with the Movie Camera was released in 1929, cataloguing the potential of the film medium (Macleod in Moser 1996: ix). Of particular note were works such as Brenda Laurel and Rachel Strickland's Placeholder (1993), the Archaeology of the Mother Tongue (1993) by Toni Dove and Michael Mackenzie, and the virtual reality performance, Dancing with the Virtual Dervish: Virtual Bodies (1994), by Diane Gromola and Yacov Sharir. These projects were particularly innovative in their exploration of virtual reality environments in an art context. 
Artists such as Char Davies moved from painting to exploring virtual space in virtual environments in the early 1990s, resulting in the works Osmose (1995) and Ephémère (1998). In Osmose, the participant, or immersant', must concentrate on his or her breath as a device to navigate vertically through the spaces represented. In 'Landscape, earth, body, being, space, and time in the immersive virtual environments Osmose and Ephémère' (2003), Davies (2003:1) says that 'within this spatiality, there is no split between the observer and the observed'. She argues that this is not tied to a Cartesian paradigm, but rather allows 'another way of sensing to come forward, one in which the body feels the space very much like that of a body immersed in the sea' (Davies 2003: 1). In this private virtual space, by 'leaving the space of one's usual sensibilities, one enters into communication with a space that is psychically innovating ... For we do not change place, we change our nature' (Bachelard [original 1966] in Davies 1997: 3).

\section{On travelling in outer space}

It seems that another way of sensing also comes forward when physically leaving the space of our usual sensibilities, when travelling in outer space, or when experiencing zero gravity (created through parabolic flight conditions). When we lose the pressure of what holds us to the earth's surface on our bodies (what enables us to travel in the way we understand), and experience the lack of gravity as a condition of the experience, new sensibilities emerge. UK-based Science-Art agency, The Arts Catalyst, has been supporting artists' and scientists' exploration of zero gravity conditions since the early 2000s. As Nicola Triscott explains, 'to defy gravity is to defy the accepted, the unquestioned and the status quo. It is to embrace the unknown and to map a new territory, personal, artistic and political' (Triscott in Triscott and La Frenais 2005: 6). 
An example of a rather playful project supported by The Arts Catalyst is that of Ansuman Biswas and Jem Finer's Zero Genie (2001), where feats performed by 'genies and flying carpets of ancient myth' (Triscott and La Frenais 2005: 56) are recreated in zero gravity conditions. According to Triscott and La Frenais, the project questions whether the realities of shamanistic technologies are any less real than those of astronauts and cosmonauts suggesting any 'judgements of fantasy and reality are conditioned by relationships of power' (Triscott and La Frenais 2005: 56).

Kitsou Dubois is a choreographer who has been exploring the experience of zero gravity movement for a number of years. Through this work she cites a number of key references in zero gravity movement, such as the subjective vertical, continuous motion and the consciousness of the 'space between' as states associated with parabolic flight. Dubois suggests that in the space of weightlessness 'there is no need for a sense of balance ... extremities of the body feel less defined and there is a sense of merging with the empty space around' (Triscott and La Frenais 2005: 46). Parallels of the experience can be seen in the descriptions given by Char Davies of the experience of travelling through the virtual space of Osmose (1995) above. This uncertainty of the body in extremes of space is reflected in a changing relationship to embodied aspects of day-today experience in our existence in the virtual space of new technologies.

\section{On travelling without leaving}

The work that defines the early exploration of telepresence in telematic spaces by artists engaged with technology is that of UK-based artist Paul Sermon and his work Telematic Dreaming (1992), which Dixon (2007: 220) describes as a 'wonderful, exquisitely simple and ground-breaking installation [that] creates a type of magic, a sort of lucid 
dream'. Over the last two decades, Sermon has built upon this very simple concept of two geographically remote spaces being connected in time. In Telematic Dreaming, images of two beds, one in Finland and the other in England, are projected onto each other, enabling a real-time interaction with the performer in one space and the visitor in the other (Sermon 1992). This new form of telematic experience enabled the participant to 'travel', or rather to be 'present', in another space through the use of technology. Susan Kozel writes an interesting account of her experience of being the performer in this piece in Spacemaking: Experiences of a Virtual Body (1994), noting that 'telepresence has been called an out-of-body experience, yet what intrigues me is the return to the body which is implied by any voyage beyond it' (1994). She continues to discuss the claim of artists such as Myron Krueger that virtual technology changes what it means to be human and alters human perception but suggests that it does not 'simply refer to the voyage out, but the inevitable return and the lasting effect that the outward motion leaves on the reunited body' (Kozel 1994).

Working within the realm of Art and Technology (and as an artist who engages with narrative as method), my own exploration of virtual space over the last decade has often been based on the retelling of narratives in a new context. An early practice-based project was to re-interpret Italo Calvino's Invisible Cities (1997) through an interactive artefact. The story was of Marco Polo's adventures to imagined cities, with Calvino providing the descriptions of the fantastic, symbolic and often conceptually based places. How do we travel without a map? Of note were my closing remarks where I suggested that the creation of a figure in the virtual space, that of Eleni, was worthy of further study, 
... to produce Wandering Fictions for the web remained essential for the concept. The impact on the process, above technical constraints, of constructing a character to exist within this space was continually evident. The net space, if it has borders and boundaries, are not yet visible. A very different potential space could still emerge. (Doyle 2000: 24)

Following my introduction to Second Life in 2007, it was a relatively short time before I created Wanderingfictions Story. The origin of the maiden name was based on media archaeologist Siegfried Zielinksi's early writings on the Internet, in which he notes that

In the motion of crossing a border, heterology encircles the impossible place, that is unlocatable, that is actually empty, that in practice is created in the motion of crossing the border $[\ldots]$ this is what taking action at the border, that which I call subjective, targets in relation to the Net: strong, dynamic, nervous, definitely process-orientated aesthetic constructions, that are introduced into the Net as Wandering Fictions. (Zielinski 1996: 285)

Having already developed a number of artist projects utilizing and investigating Second Life as a space for artistic experimentation, in 2009 my interest in the notion of Wanderingfictions Story as a manifestation of, and from, virtual space became the basis of a new project, Meta-Dreamer (2009). After reflecting on artist Joseph DeLappe's MGandhi series, ${ }^{1}$ I began working with digital materialization expert Turlif Vilbrandt ${ }^{2}$ to create a series of digitally materialized objects of Wanderingfictions Story. By 
experimenting with digital processes that extracted data from Second Life and investigating different types of materials, attempts were made to represent jade, and clouded glass, among other textures. The end result can be seen in Figure 1; the qualities of the figure are cloud-like and ethereal as though Wanderingfictions Story, the meta-dreamer, is 'almost there'. The digital object was presented in the Golden Thread Gallery space (as part of the ISEA $2009^{3}$ exhibition) alongside DeLappe's figure of MGandhi 1 (2008). The visitor could also experience the virtual installation on Kriti Island ${ }^{4}$ that included the presentation of Wanderingfictions Story, the meta-dreamer, through captured images and her meta-dream writing.

Figure 1: Wanderingfictions Story as part of the Meta-Dreamer project at the Golden Thread Gallery, Belfast C (2009) Denise Doyle. Digital Object.

\section{On not travelling at all}

Ah, so you are a map maker! I wonder what remarks you make of the landscapes that you travel through? Do you have a system of classification at all? Of patterning? Is it to 'capture' what it is to be here or to be there? I'm uncertain of my own geography. I don't even know where I live. Conceptually, that is. If we looked on the map I would not be able to point to it and say 'there, that is where I live, that is my home'. Perhaps this is something that happens with a virtual geography. (Doyle and Kim 2007: 214-15) 
Moving through space (and time) is our basic level of experiential knowledge, as we exist in the physical world. Geographer Doreen Massey, in an essay responding to the work of artist Olafur Eliasson, attempts to illustrate a set of relationships between time and space by using a narrative account of a journey between Manchester and Liverpool in the United Kingdom. In the process of travelling she suggests, 'if movement is reality itself then what we think of as space is a cut through all those trajectories; a simultaneity of unfinished stories' (Massey 2003: 111). Further,

space has its times. To open up space to this kind of imagination means thinking about time and space together. You can't hold places and things still. What you can do is meet up with them ... 'Here', in that sense is not a place on a map. It is that intersection of trajectories. (Massey 2003: 111, original emphasis)

Two interesting points emerge from this argument; first, if each space has a particular time, as Massey implies, then it could be that virtual world spaces also have a particular time (or times) attached to them. Not only then could there be different sets of timespaces that may be located in the Second Life, but the space could enable a particular reflection upon different time-spaces as phenomenal experience. Second, if 'place' can be considered an intersection of trajectories of unfinished stories, does this challenge our understanding and articulation of what place is? Does this also force us to rethink the notion of the traveller? Is 'place', in fact, physical at all? 
An artist residency in India $^{5}$ revealed that distinct folk art practices have developed in very specific regions, and can even be linked to individual villages in the state of West Bengal. These folk art practices are intrinsically connected to (and are born out of) place. Certain parallels already exist between the virtual space of Kriti Island and the real places in West Bengal. Wanderingfictions Story (my avatar and virtual counterpart) 'wanders' in her virtual place, just as the Bauls and Fakirs (minstrels) 'wander' through their place in the eastern region of the state (having already inspired many of the writings of the well-known Indian writer and poet, Rabindranath Tagore). Professor of Philosophy Edward Casey considers that

there is no knowing or sensing a place except by being in that place and to be in a place is not, then, subsequent to perception ... but is an ingredient of perception itself. Such knowledge, genuinely local knowledge, is itself experiential. (Casey 1997: 18)

Yet Massey suggests that places should not be considered 'as points or areas on map, but as integrations of space and time, as spatio-temporal events' (Massey 2005: 130, original emphasis). Perhaps an understanding of place should be multi-layered and draw from a range of views in attempting to consider moreover the 'specificity of place' itself (Massey 2005: 130).

In her Atlas of Remote Islands: Fifty Islands I Have Not Visited and Never Will, writer Judith Schalansky (2009: 10) suggests that 'the lines on a map prove themselves to be artists of transformation: they crisscross in cool mathematical patterns ... they ensure the earth retains its physicality'. Having never travelled to these real islands (and never 
intending to), Schalansky pieces together information and descriptions of these imagined, yet real places. Comparing the earth represented as a globe and through the atlas she writes,

... this Earth has no borders, no up or down, no beginning and no end [whereas] in an atlas, the Earth is as flat as it was before explorers pinned down the white spaces of enticingly undiscovered regions with contours and names, freeing the edges of the world from the sea monsters and other creatures that had long held sway there. (Schalansky 2009: 11)

Rapa Iti, Pingelap and Clipperton Atoll are but three of the 50 islands that are described by Schalansky (it is hard not to imagine Kriti Island to be the 51 of Schalansky's Islands, full of stories yet to be told). Rapa Iti is forty square kilometres with 482 inhabitants and lies in the Pacific Ocean as part of French Polynesia. Marc Liblin, who lived near the foothills of the Vosges in France, dreamt that he speaks an unknown language. Eventually he meets an old woman who speaks the old Rapa of her homeland. Liblin, 'who has never been outside Europe, marries the only woman who understands him, and in 1983 he leaves with her for the island where his language is spoken' (Schalansky 2009: 72). A total of 75 of the 250 inhabitants of Pingelap in the Caroline Islands see no colour, "not the fiery crimson of the sunset, not the azure of the ocean ... Silly talk about the gloriousness of colour makes them indignant' (Schalansky 2009: 98). Clipperton Atoll, with barely two kilometres of land, is uninhabited. Schalansky suggests that the very construction of an island lends itself to narrative, or to stories in 
literature (everything becomes a stage): 'The absurdity of reality is lost on the large land masses, but here on the islands, it is writ large. An island offers a stage: everything that happens on it is practically forced to turn into a story, into a chamber piece in the middle of nowhere, into the stuff of literature' (2009: 19-20).

If Kriti Island were to be described in similar ways (if her stories could be told), the space (or place) would not be unlike the islands described by Schalansky (2009). When Kriti Island was specifically placed almost adjacent to the virtual island of Symobia in 2007, there was barely another island nearby. Now, in 2013 it is as though Kriti has become part of an archipelago of islands. Beyond its locality, it is hard to determine the situation of Kriti with any geographical certainty - even now, six years on. But when I try and 'imagine' the differences and similarities between the real islands in Schalansky's atlas and Kriti, their differences seem to fade and their similarities strengthen - the island offering up a stage writ large.

\section{Conclusion}

As we rethink the traveller at the beginning of the twenty-first century, we realize there are now many new forms of travel, and each form holds its own poetics (and politics) travel as embodied, remembered, imagined, even as fictive travels of the mind (the traveller no longer necessarily even needs to leave her home). Bachelard, writing in The Poetics of Reverie (1969), uses the curious analogy of how in tranquil water 'depth and surface are reconciled. The deeper the water the clearer the mirror... depth and surface belong to one another' (1969:197). New technologies explored by Paul Sermon (Telematic Dreaming, 1992) and Char Davies (Osmose 1995 and Ephémère 1998) point to new relationships in virtual space, experienced as real and sometimes offering 
entirely new spatial experiences; perhaps depth and surface has a resonance here too. Equally, the explorations of artists (and scientists) and dancers, such as Kitsou Dubois, point to new relationships of the body, space and travel. As the real and imagined are no longer strangers (or opposites), it is also true that the physical and the virtual have become more firmly entangled.

Whether travelled to physically, or in the imagination, the experience of a place can be as a mathematical pattern on a map, or as a virtual island on a virtual grid, or even as a real place imagined. In the accounts of those who have experienced zero gravity conditions, and those who have experienced their virtual bodies - the heterogeneity of the experiences points towards a complex interweaving of the virtual and the physical, and that of the body with space and place. The question of what is real, and what is fiction, has always been a tenuous one, and this premise is demonstrated in the stories and descriptions of the islands on Schalansky's (2009) map. The narratives are written based on fact, and yet these embellished stories allow us to see the world slightly differently, revealing stories that allow us to make another sense of the world and to understand a little more our passion to understand and experience the extreme spaces of the unknown.

\section{References}

Bachelard, G. ([1943] 1988) Air and Dreams: An Essay on the Imagination of Movement (trans. E. R. Farrell and C. F. Farrell), Dallas: The Dallas Institute Publications. 
(1969), The Poetics of Reverie: Childhood, Language and the Cosmos, Boston:

Beacon Press.

Calvino, I. (1997), Invisible Cities, London: Vintage.

Casey, E. (1997), 'How to get from space to place in a fairly short stretch of time', in S.

Feld and K. Basso (eds), In Senses of Place, Santa Fe, New Mexico: School of American Research Press, pp. 13-52.

Damer, B. (1998), Avatars! Exploring and Building Virtual Worlds on the Internet, Berkeley, California: Peachpit Press.

Davies, C. (1995), Osmose, virtual reality environment, http://www.immersence.com/osmose/index.php. Accessed 28 February 2016.

(1997), 'Changing space: Virtual reality as an arena of embodied being', in R.

Packer and K. Jordan (eds), Multimedia: From Wagner to Virtual Reality, New York:

W.W. Norton \& Company, http:///www.immersence.com. Accessed 28 February 2016.

(1998), Ephémère, virtual reality environment, http://www.immersence.com/.

Accessed 28 February 2016. 
(2003), 'Landscape, earth, body, being, space, and time in the immersive virtual environments Osmose and Ephemere', in J. Malloy (ed.), Women, Art and Technology, Cambridge, MA and London: MIT Press, http:///www.immersence.com._Accessed 28 February 2016.

Dixon, S. (2007), Digital Performance: A History of New Media in Theater, Dance, Performance Art, and Installation, Cambridge, MA: MIT Press.

Dove, T. and Mackenzie, M. (1993), Archaeology of the Mother Tongue, virtual reality installation, Alberta, Canada: Banff Centre for the Arts, http://www.banffcentre.ca/bnmi/coproduction/archives/a.asp. Accessed 20 April 2016.

Doyle, D. (2000), 'Wandering Fictions 2.0: Eleni's Journey', Digital Media, Coventry: Coventry University.

(2010), 'Art and the emergent imagination in avatar-mediated online space', Ph.D. thesis, SMARTlab Digital Media Institute, London: University of East London.

Doyle, D. and Kim, T (2007), 'Embodied narrative: The virtual nomad and the meta dreamer', The International Journal of Performance Arts and Digital Media, 3:2\&3, pp. 209-22. 
Ettlinger, O. (2009) The Architecture of Virtual Space, Ljubljana: University of Ljubljana.

Grau, O. (2003), Virtual Art: From Illusion to Immersion, Cambridge, MA: MIT Press.

Gromola, D. and Sharir, Y. (1994), Dancing with the Virtual Dervish: Virtual Bodies, virtual reality installation, Alberta, Canada: Banff Centre for the Arts, http://www.banffcentre.ca/bnmi/coproduction/archives/d.asp\#dancing. Accessed 20 April 2016.

Grosz, E. (2001), Architecture From the Outside: Essays on Virtual and Real Space, Cambridge, MA: MIT Press.

Heim, M. (1993), The Metaphysics of Virtual Reality, New York: Oxford University Press.

Heudin, J. C. (ed.) (1999), Virtual Worlds: Synthetic Universes, Digital Life and Complexity, Reading, MA: Perseus Books.

Jones, D. E. (2006), 'I, Avatar: Constructions of self and place in second life and the technological imagination', Gnovis, Journal of Communication, Culture and Technology, 1:2 http://gnovis.georgetown.edu. Accessed 20 April 2016. 
Kozel, S. (1994), 'Spacemaking: Experiences of a virtual body', http://art.net/ dtz/kozel.html. Accessed 17 February 2016.

Lappe, J. De (2008a), Re-enactment: The Salt Satyagraha Online, http://saltmarchsecondlife.wordpress.com/. Accessed 20 April 2016.

(2008b), Tourists and Travelers, New York: Eyebeam Gallery, http://eyebeam.org/events/tourists-and-travelers. Accessed 20 April 2016.

Laurel, B. and Strickland, R. (1993), Placeholder, virtual reality installation, Canada: Banff Centre for the Arts, Alberta, http://www.banffcentre.ca/bnmi/coproduction/archives/p.asp\#placeholder Accessed 20 April 2016.

Lefebvre, H. (1991), The Production of Space, Oxford: Blackwell Publishing.

Lindstrand, T. (2007), 'Viva Pinata: Architecture of the everyday', in V. F. Borries, M. Bottger and S.P. Walz (eds), Space Time Play: Computer Games, Architecture and Urbanism - the Next Level, Basel: Birkhauser Verlag AG. 
Massey, D. (2003), 'Some times of space', in S. May (ed.), Olafur Eliasson: The Weather Report, London: Tate Publishing.

(2005), For Space, London: Sage Publications.

Morris, M. (1988), Nothing to Declare, Boston: Houghton Mifflin Harcourt.

Moser, M. A. (ed.) (1996), Immersed in Technology: Art and Virtual Environments, Cambridge, MA: MIT Press.

Rheingold, H. (1991) Virtual Reality, New York: Summit Books.

Schalansky, J. (2009), Atlas of Remote Islands: Fifty Islands I have not Visited and Never Will, London: Particular Books.

Schroeder, R. (ed.) (2002), The Social Life of Avatars: Presence and Interaction in Shared Virtual Environments, London:Springer.

Sermon, P. (1992), Telematic Dreaming, performance installation, http://creativetechnology.salford.ac.uk/paulsermon/dream/. Accessed 20 April 2016. 
Soja, E. W. (1996), Thirdspace: Journeys to Los Angeles and other Real-and-Imagined Places, Malden, MA and Oxford: Blackwell Publishers.

Stockburger, A. (2007), 'Playing the third place: Spatial modalities in contemporary game environments', International Journal of Performance Arts and Digital Media, $3: 2 \& 3$, pp. 223-36.

Tagore, R. ([1916] 2011), Stray Birds, Knockeven, Ireland: Salmon Poetry.

Triscott, N. and La Frenais, R. (2005), ZeroGravity: A Cultural User's Guide, London: The Arts Catalyst.

Zielinski, S. (1996), 'Thinking the border and the boundary', in T. Druckrey (ed.),

Electronic Culture: Technology and Visual Representation, Canada: Aperture Foundation.

\section{Contributor details}

Denise Doyle has a background in Fine Art Painting and Digital Media. She is an Artist-Researcher, Senior Lecturer in Digital Media at the University of Wolverhampton, and Adjunct Professor in Virtual Worlds and Digital Practice, Ontario 
College of Art and Design University (OCAD U), Toronto, Canada. Denise has published widely on the subject of the virtual and the imaginary, the experience of the avatar body in virtual worlds and game spaces, and the use of virtual worlds for creative practice. Denise is currently co-editing the Metaverse Creativity Journal, Intellect and sits on two other editorial boards: International Journal of Performance Arts and Digital Media (Routledge) and Journal of Gaming and Virtual Worlds (Intellect). She recently edited New Opportunities for Artistic Practice in Virtual Worlds (IGI Global, 2015) bringing together artists, practitioners, and theorists, to consider the significance of virtual worlds and avatar-based interaction for artistic practice. Her research interests include: virtual worlds, art-sci dialogues, interactive film, philosophies of the imagination, practice-based research methods and digital narratives. She is currently developing a series of projects exploring digital embodiment in art and technology.

Contact:

Dr Denise Doyle

Senior Lecturer Digital Media

Faculty of Arts

MK616 George Wallis Building

Wolverhampton

WV1 1SB

UK

D.Doyle@wlv.ac.uk 
${ }^{1}$ During an artist residency at the eyebeam Gallery, New York, in 2008 Joseph DeLappe experimented with a range of data materialization processes to produce MGandhi 1 (8" rapid prototyped 3D print), MGandhi 2 (15" rapid prototyped 3D print finished in genuine gold leafe) and MGandhi 3 (a 17' tall monumental sculpture constructed from cardboard and hot glue).

${ }^{2}$ Turlif Vilbrandt is an expert in the field of Digital Materialisation.

${ }^{3}$ The Inter Society for electronic Arts organizes an annual symposium and related exhibitions. In 2009 it was held in Belfast on the Island of Ireland.

${ }^{4}$ Kriti Island was an art laboratory in Second Life that I set up in 2007 with the intention of exploring and hosting artistic explorations of virtual space. The island was discontinued in 2014.

${ }^{5}$ This artist residency in spring 2011 brought together a group of six artists, musicians and dancers from the United States, United Kingdom and Eire and a group of West Bengal folk artists working with Banglanatak.com, Calcutta (organized through the India FOLKNEST ethno-Magic Going Global (EGG) Project funded through the EU and UNESCO India). 